\title{
KELENGKAPAN RESUME MEDIS DAN KEAKURATAN KODE DIAGNOSIS BPJS RAWAT INAP DI RSUP DR. M. DJAMIL PADANG, INDONESIA
}

\section{COMPLETENESS OF MEDICAL RESUME AND ACCURACY OF INPATIENT BPJS CLAIM CODE IN THE GENERAL HOSPITAL DR. M. DJAMIL PADANG, INDONESIA}

\author{
Ropendi Pardede $^{1^{*}}$, Lissa Hamama ${ }^{2}$ Edison $^{3}$ \\ ${ }^{1,3}$ Stikes Syedza Saintika Padang \\ ${ }^{2}$ Instalasi Rekam Medis RSUP DR. M. Djamil Padang \\ *Email:ropendipardede02@gmail.com,082268536563
}

Submitted : 2020-10-25, Reviewed : 2020-11-23, Accepted : 2020-11-24

\begin{abstract}
ABSTRAK
Resume medis dan keakuratan kode diagnosa adalah satu kesatuan yang tidak bisa dipisahkan dari klaim BPJS rawat inap. Jumlah pending klaim BPJS rawat inap RSUP Dr. M. Djamil Padang per bulan berkisar 170 berkas. Tujuan penelitian ini adalah menganalisis kelengkapan resume medis dan keakuratan kode diagnosa klaim BPJS rawat inap. Jenis penelitian yang digunakan adalah penelitian kualitatif dengan metode observasi wawancara. Informan berjumlah 9 orang. Metode pengumpulan data dengan wawancara mendalam (Indepth Interview), observasi lapangan dan telaah dokumen. Analisa data menggunakan teknik triangulasi. Berdasarkan hasil penelitian didapatkan komponen input menunjukan tenaga pengisian resume medis adalah dokter residen, tenaga coder adalah lulusan D3 Rekam, sarana dan prasarana untuk kelengkapan resume medis masih kurang, sedangkan untuk pengkodean sudah mencukupi, SOP secara tertulis sudah ada namun tidak tersebar di semua bagian. Untuk komponen proses kelengkapan resume medis masih ada kekurangan, untuk pengkodean masih ada tenaga coder yang melakukan pengkodean tanpa merujuk ICD 10 dan ICD 9 CM. Validasi resume medis dan validasi kode diagnosa dilakukan oleh case manager. Analisis Kelengkapan Resume Medis dan Keakuratan Kode Diagnosa di RSUP Dr. M. Djamil Padang belum terlaksana berdasarkan Surat Keputusan Direktur Utama RSUP Dr. M. Djamil Padang YR.01.01/XVI.I/204/2018 dan PMK no 76 tahun 2016. Diharapkan RSUP Dr. M. Djamil Padang dapat memperhatikan dokter dan coder mulai dari kepatuhan terhadap peraturan dan kebijakan yang berlaku, agar kelengkapan resume medis dan keakuratan kode diagnosa bisa tercapai sesuai harapan.
\end{abstract}

Kata Kunci: Kelangkapan, Keakuratan, Kode, Diagnosis

\section{ABSTRACT}

Medical resume and accuracy of the diagnostic code are an inseparable part of the BPJS inpatient claim. The number of pending claims of BPJS inpatient Dr. M. Djamil Padang per month around 170 files. The purpose of this study was to analyze the completeness of the medical resume and the accuracy of the BPJS claim diagnosis code. This type of research is qualitative research with the interview observation method. There were 9 informants. Methods of data collection by in-depth interviews, field observations, and document review. Data analysis uses triangulation techniques. The completeness of the medical resume and the accuracy of the diagnosis of the claim is still not optimal, there are still incomplete medical 
resumes and diagnostic codes pending by the BPJS. There are still coders who do the coding by relying on having memorized the code without referring back to the ICD 10 and ICD 9 CM books so that there are still codes that are not suitable and inaccurate. The completeness of the medical resume and the accuracy of the claim diagnosis code has been running so far, but it has not been maximized and not fully following the policy of the Decree of the Managing Director of RSUP Dr. M. Djamil Padang YR.01.01 / XVI. I / 204/2018 Dated January 8, 2018, and PMK No. 76 of 2016, where there are still pending claims and still need to be fixed.

Keywords: Completeness of Medical Resume and Accuracy of Diagnosis Cod

\section{PENDAHULUAN}

Undang-undang Republik Indonesia Nomor 40 Tahun 2004 tentang Sistem Jaminan Kesehatan Sosial Nasional (SJSN), mempunyai tujuan untuk menjamin agar peserta memperoleh manfaat pemeliharaan kesehatan dan perlindungan dalam memenuhi kebutuhan dasar kesehatan. Hal ini sesuai dengan salah satu tujuan dari Millenium Development Goals (MDGs) yaitu mentargetkan tercapainya derajat kesehatan di seluruh dunia. Salah satu upaya yang dilakukan oleh pemerintah Indonesia untuk meningkatkan kesehatan yaitu dengan mengadakan program Jaminan Kesehatan Nasional (JKN) per Januari 2014 (BPJS, 2014). Sistem Jaminan Sosial Nasional (SJSN) merupakan program negara yang bertujuan memberikan kepastian perlindungan dan kesejahteraan sosial bagi seluruh rakyat. Badan Penyelenggaraan Jaminan Sosial (BPJS) adalah badan hukum publik yang dibentuk untuk menyelenggarakan program jaminan sosial. BPJS Kesehatan adalah badan hukum yang dibentuk untuk menyelenggarakan program jaminan kesehatan. Peserta BPJS Kesehatan dibagi menjadi dua kelompok, yaitu Penerima Bantuan Iuran (PBI) dan Mandiri (Undang Undang Nomor 24 Tahun 2011, 2011). Menurut Buku Panduan Praktis Administrasi Fasilitas Kesehatan BPJS, kelengkapan informasi sangatlah penting untuk proses pembayaran klaim tagihan pasien pada fasilitas kesehatan. Kelengkapan informasi yang dimaksud yaitu kelengkapan informasi medis yang bersumber dari resume medis yang merupakan bagian dari dokumen rekam medis dan merupakan salah satu syarat yang harus ada pada saat pengajuan klaim tagihan pasien rawat inap. Oleh karena itu petunjuk verifikasi klaim disusun secara khusus dengan tujuan agar dapat menjadi acuan bagi verifikator BPJS Kesehatan maupun bagi fasilitas kesehatan dalam rangka menjaga mutu layanan dan efisiensi biaya pelayanan kesehatan bagi peserta BPJS Kesehatan (BPJS et al., 2014). Mengingat resume medis merupakan bagian dari dokumen rekam medis berupa lembaran yang sangat penting dan mendasar dalam formulir rawat inap dan menjadi bukti yang dilampirkan pada saat klaim, maka kelengkapan isinya menjadi tanggung jawab tenaga kesehatan khususnya dokter. Adapun kegunaan resume medis yaitu untuk mengetahui secara singkat tentang keluhan utama dan keluhan penyakit sekarang. Informasi yang terkandung didalam resume medis yang menjadi pedoman dalam keakuratan kode diagnosa yang nantinya akan diakui oleh pihak BPJS Kesehatan dalam proses klaim terdiri dari indikasi pasien dirawat, riwayat penyakit (anamnesis), pemeriksaan fisik, pemeriksaan diagnostik dan laboratorium, tindakan diagnostik/prosedur terapi dan obat 
yang diberikan selama pasien dirawat inap (Kemenkes, 2014). Informasi medis yang terdapat dalam resume medis tersebut akan mendukung tenaga coder dalam melakukan pengkodean diagnosa secara akurat berdasarkan ICD-10 dan mengacu kepada buku Pedoman PMK Nomor 76 Tahun 2016/Peraturan Menteri Kesehatan Nomor 76 Tahun 2016 tentang Pedoman IndonesianCase Base Groups (INA-CBG) dalam Pelaksanaan Jaminan Sosial Kesehatan Nasional. Keakuratan kode diagnosa sangat mempengaruhi kualitas pembayaran biaya kesehatan dengan sistem case-mix (PMK 76 Tentang Pedoman Indonesian Case Based Groups (INA CBG's) Dalam Pelaksanaan Jaminan Kesehatan Nasional, 2016). Keakuratan dalam pemberian kode diagnosa merupakan hal yang harus diperhatikan oleh tenaga perekam medis/coder, ketepatan data diagnosa sangat penting dibidang manajemen data klinis dan dalam hal penagihan biaya kepada pihak BPJS Kesehatan beserta hal-hal lain yang berkaitan dalam asuhan dan pelayanan kesehatan (Hatta, 2014).

Menurut penelitian yang dilakukan oleh Wariyanti (2013), berdasarkan hasil penelitian yang telah dilaksanakan di RSUD Kabupaten Karanganyar pada bulan April 2014 dengan jumlah sampel yaitu dokumen rekam medis pasien rawat inap sebanyak 44 dokumen rekam medis. Dari hasil yang didapat tergambar bahwa tingkat kelengkapan dokumen rekam medis dengan kategori lengkap berjumlah $15(34,10 \%)$ dan dokumen rekam medis dengan kategori tidak lengkap berjumlah $29 \quad(69,10 \%)$. Dokumen rekam medis dengan tingkat keakuratan diagnosanya akurat sejumlah $18(59,90 \%)$ dan tidak akurat berjumlah $26 \quad(40,10 \%)$. Dokumen rekam medis dengan tingkat kelengkapan informasi medis lengkap dan pemberian kode diagnosa akurat sejumlah $10 \quad(66,67 \%)$, sedangkan dokumen rekam medis dengan tingkat kelengkapan informasi medis lengkap tetapi pemberian kodenya tidak akurat sejumlah $5(33,33 \%)$, dokumen rekam medis yang tidak lengkap informasi medis namun akurat sejumlah 8 $(27,59 \%)$, dan dokumen rekam medis dengan tingkat kelengkapan informasi medis tidak lengkap serta tidak akurat sejumlah $21 \quad(72,41 \%)$. Hal ini disebabkan oleh pengetahuan dan dokter yang tidak patuh dalam mengisi dokumen rekam medis, pengetahuan coder serta kurangnya komunikasi antara coder dengan dokter (Wariyanti, 2016). Menurut penelitian yang dilakukan oleh Saputri (2015), berdasarkan hasil penelitian yang telah dilaksanakan di RSUD Pandan Arang Boyolali menyatakan bahwa pelaksanaan pengisian informasi dokumen rekam medis belum sesuai dengan standar pelayanan minimal rekam medis yang harus $100 \%$ terisi pelaksanaan tindakan dan prosedur dikarenakan kurang telitinya petugas dalam melengkapi dokumen rekam medis. Pada keakuratan kode diagnosa masih terdapat proses pelaksanaan yang tidak sesuai dengan SPO, dimana masih ada petugas coder yang melakukan pengkodean diagnosa tanpa menggunakan ICD-10 karena petugas merasa sudah hafal dengan kode diagnosa tersebut tanpa memastikan kembali kode tersebut pada buku ICD-10 dan petugas coder yang kurang teliti dalam mengkode diagnose (Saputri, 2015).

Berdasarkan studi pendahuluan yang dilakukan di Instalasi Rekam Medis Rumah Sakit Umum Pusat Dr. M. 
Djamil Padang diperoleh kode diagnosa klaim BPJS yang tidak akurat sebesar $80 \%$ dan yang akurat sebesar $20 \%$. Dari 20 resume medis yang di teliti terdapat 2 resume medis yang tidak lengkap pengisian anamnesisnya, terdapat 3 resume medis yang tidak lengkap pengisian pemeriksaan fisiknya, terdapat 7 resume medis yang tidak lengkap pengisian pemeriksaan diagnostik dan laboratoriumnya, terdapat 5 resume medis yang tidak lengkap pengisian tindakan diagnostik/prosedur terapinya, dan 3 resume medis yang tidak lengkap pengisian obat yang diberikan selama dirawat. Hal ini disebabkan resume medis yang di isi atau dibuat bukan oleh dokter spesialis langsung tetapi oleh dokter residen sehingga kurangnya pengetahuan dan kepatuhan dokter dalam pengisisan rekam medis, pengetahuan tenaga coder dalam melakukan pengkodean menurut ICD-10 dan buku Pedoman PMK Nomor 76 Tahun 2016 serta kurangnya komunikasi antara tenaga coder dengan dokter. Apabila kode yang dibuat pada klaim tagihan rawat inap ke pihak BPJS Kesehatan tidak akurat, maka klaim tagihan akan di pending/belum layak untuk dibayarkan bahkan bisa sampai tidak dibayarkan sehingga dapat berdampak pada biaya pelayanan kesehatan.

\section{BAHAN DAN METODE}

Penelitian ini merupakan penelitian kualitatif mengenai kelengkapan resume medis dan keakuratan kode diagnosa klaim BPJS Kesehatan di Rumah Sakit Umum Pusat Dr. M. Djamil Padang.Waktu penelitian dilakukan pada bulan Maret 2020 di Rumah Sakit Umum Pusat Dr. M. Djamil Padang.Waktu penelitian dilakukan pada bulan Maret 2020 di
Rumah Sakit Umum Pusat Dr. M. Djamil Padang. Pada penelitian kualitatif, peneliti melakukan wawancara mendalam dengan orang-orang yang dipandang tahu dan berhubungan dengan tujuan penelitian tersebut. Teknik penentuan informan secara purposive sampling dalam penelitian ini dilakukan dengan pertimbangan:

1. Informan mengetahui masalah secara lebih luas dan mendalam sehubungan dengan objek penelitian.

2. Informan dapat dipercaya dan kompeten sebagai sumber data sehubungan dengan objek penelitian.

Adapun informan pada penelitian ini sebanyak 9 (sembilan) orang yaitu 1 orang kepala kepala instalasi rekam medis, 1 orang penanggung jawab rawat inap, 3 orang dokter, 3 orang coder dan 1 orang case manager. Cara pengumpulan data dilakukan dengan wawancara mendalam (indepth interview), observasi, dan telaah dokumen.

Semua data yang telah dikumpulkan dianalisis dengan pendekatan analisis isi, yaitu membandingkan dengan teori-teori yang ada dan tinjauan pustaka. Analisa dilakukan secara kualitatif dengan pembahasan secara deskriptif terhadap unsur proses dengan berbagai metode :

1. Triangulasi teknik atau metode yaitu dengan melakukan wawancara mendalam, observasi dan check list.

2. Triangulasi sumber yaitu dengan crosscheck dengan sumber data lain,

3. membandingkan dan melakukan kontras data, serta menggunakan kategori informan yang berbeda (Sugiyono, 2016). 


\section{HASIL}

Table 1. Daftar Informan Wawancara Mendalam

\begin{tabular}{cll}
$\begin{array}{c}\text { Kode } \\
\text { Informan }\end{array}$ & \multicolumn{1}{c}{ Jabatan } & \multicolumn{1}{c}{ Pendidikan } \\
Inf 1 & Kepala Instalasi Rekam Medis D3 Rekam Medis \\
Inf 2 & $\begin{array}{l}\text { Penanggung Jawab Rekam } \\
\text { Medis }\end{array}$ & D3 Rekam Medis \\
& Denf & \\
Inf 3 & Dokter & Dokter Umum \\
Inf 4 & Dokter & Dokter Umum \\
Inf 5 & Dokter & Dokter Umum \\
Inf 6 & Coder & D3 Rekam Medis \\
Inf 7 & Coder & D3 Rekam Medis \\
Inf 8 & Coder & D3 Rekam Medis \\
Inf 9 & Case Manager & Dokter Umum \\
\hline
\end{tabular}

Dalam penelitian ini, pengambilan sampel dilakukan dengan wawancara mendalam (indepth interview) terhadap informan terkait dengan kelengkapan resume medis dan keakuratan kode diagnosa klaim BPJS rawat inap di Rumah Sakit Umum Pusat Dr. M. Djamil Padang serta didukung dengan hasil observasi yang dilakukan oleh peneliti.Wawancara mendalam dilakukan pada 9 (Sembilan) orang informan terdiri dari kepala Instalasi Rekam Medis, penanggung jawab rawat inap, 3 (tiga) orang dokter, 3 (tiga) orang coder dan case manager (Table 1).

Berdasarkan matrik triangulasi di atas dapat disimpulkan bahwa kelengkapan resume medis dan keakuratan kode diagnosa klaim sudah berjalan selama ini, namun belum maksimal dan belum sepenuhnya sesuai dengan kebijakan Surat Keputusan Direktur Utama RSUP Dr. M. Djamil Padang YR.01.01/XVI.I/204/2018 Tanggal 8 Januari 2018 dan PMK no 76 Tahun 2016, dimana masih ada klaim pending dan masih harus diperbaiki. Hal ini sudah mengganggu alur pengklaiman dimana seharusnya resume sudah harus lengkap dan kode diagnosa sudah harus akurat pada saat ditagihkan ke pihak BPJS, sehingga tidak ada lagi pending dari pihak BPJS dan tagihan rumah sakit sudah bisa dibayarkan oleh pihak BPJS dengan cepat dan sesuai kesepakatan (Table 2)

Table 2. Matrik Triangulasi Kelengkapan Resume Medis dan Keakuratan Kode Diagnosa Klaim BPJS Rawat Inap Triangulation

\begin{tabular}{lllll}
\multicolumn{1}{c}{ Topik } & \multicolumn{1}{c}{$\begin{array}{c}\text { Indepth } \\
\text { Interview }\end{array}$} & \multicolumn{1}{c}{$\begin{array}{c}\text { Telaah } \\
\text { Dokumen }\end{array}$} & \multicolumn{1}{c}{ Observasi } & \multicolumn{1}{c}{ Kesimpulan } \\
Kelengkap & Pengisian resume & - Kebijakan Surat & Kelengkapan & \multicolumn{1}{c}{ Kelengkapan } \\
an Resume & sudah bagus, karena & Keputusan & resume medis dan & resume medis dan \\
Medis dan & mengarah ke & Direktur Utama & keakuratan diagnosakeakuratan kode \\
Keakurata & elektronik, kalau & RSUP Dr. M. & klaim masih masih & diagnosa klaim \\
n Kode & untuk pengkodean di & Djamil Padang & belum maksimal, & sudah berjalan \\
\hline
\end{tabular}


DOI: http://dx.doi.org/10.30633/jkms.v11i1.787

\begin{tabular}{|c|c|c|c|c|}
\hline Diagnosa & $\begin{array}{l}\text { lihat dari pending } \\
\text { BPJS (Inf 1) Resume } \\
\text { filling is good } \\
\text { because it leads to } \\
\text { electronics if you } \\
\text { look at the coding } \\
\text { from the pending } \\
\text { BPJS. } \\
\text { - Sudah berjalan } \\
\text { dengan baik, cuma } \\
\text { masih ada } \\
\text { kendala-kendala } \\
\text { misalnya diagnosa } \\
\text { yang di tulis dengan } \\
\text { dokter mungkin tidak } \\
\text { singkron atau gimana } \\
\text { atau kurang jelas } \\
\text { mungkin oleh } \\
\text { petugas kodenya, kita } \\
\text { konfirmasi balik gitu } \\
\text { (Inf 2) It has been } \\
\text { going well, only } \\
\text { there are still } \\
\text { problems, for } \\
\text { example, the } \\
\text { diagnosis written by } \\
\text { the doctor may not be } \\
\text { in sync or how or is } \\
\text { unclear perhaps by } \\
\text { the code officer, we } \\
\text { will confirm it. } \\
\text { - Kalau untuk saat ini } \\
\text { sudah sesuai, kalau } \\
\text { misalnya ada } \\
\text { kendala kita } \\
\text { komunikasikan lagi } \\
\text { dimana masalahnya, } \\
\text { dimana } \\
\text { kekurangannya, kita } \\
\text { lengkapi lagi (Inf 9) } \\
\text { If for now, it is } \\
\text { appropriate, for } \\
\text { example, if there is a } \\
\text { problem, we will } \\
\text { again communicate } \\
\text { where the problem }\end{array}$ & $\begin{array}{l}\text { YR.01.01/XVI.I/ } \\
\text { 204/2018 } \\
\text { Tanggal } 8 \text { Januari } \\
2018 \\
\text { - PMK Nomor } 76 \\
\text { Tahun } 2016 \\
\text { - Policy on Decree } \\
\text { of the President } \\
\text { Director Dr. M. } \\
\text { Djamil Padang } \\
\text { YR.01.01/ XVI.I } \\
\text { / 204/2018 on } \\
\text { January } 8,2018 . \\
\text { - PMK Number } 76 \\
\text { of } 2016 .\end{array}$ & $\begin{array}{l}\text { case manager. } \\
\text { The completeness } \\
\text { of the medical } \\
\text { resume and the } \\
\text { accuracy of the } \\
\text { claim diagnosis is } \\
\text { still not optimal, } \\
\text { there are still } \\
\text { incomplete medical } \\
\text { resumes and } \\
\text { diagnostic codes } \\
\text { pending by the } \\
\text { BPJS. However, the } \\
\text { incomplete resume } \\
\text { and the inaccurate } \\
\text { code can still be } \\
\text { repaired, repairs are } \\
\text { carried out jointly } \\
\text { by the doctor, } \\
\text { coder, and case } \\
\text { manager. }\end{array}$ & $\begin{array}{l}\text { selama ini, namun } \\
\text { belum maksimal } \\
\text { dan belum } \\
\text { sepenuhnya sesuai } \\
\text { dengan kebijakan } \\
\text { Surat Keputusan } \\
\text { Direktur Utama } \\
\text { RSUP Dr. M. } \\
\text { Djamil Padang } \\
\text { YR.01.01/XVI.I/2 } \\
\text { 04/2018 Tanggal } 8 \\
\text { Januari 2018 dan } \\
\text { PMK n0 76 Tahun } \\
\text { 2016, dimana } \\
\text { masih ada klaim } \\
\text { pending dan masih } \\
\text { harus diperbaiki. } \\
\text { Hal ini sudah } \\
\text { mengganggu alur } \\
\text { pengklaiman } \\
\text { dimana seharusnya } \\
\text { resume sudah } \\
\text { harus lengkap dan } \\
\text { kode diagnosa } \\
\text { sudah harus akurat } \\
\text { sehingga tidak ada } \\
\text { lagi pending dari } \\
\text { pihak BPJS dan } \\
\text { tagihan rumah } \\
\text { sakit sudah bisa } \\
\text { dibayarkan oleh } \\
\text { pihak BPJS } \\
\text { denagn cepat dan } \\
\text { sesuai kesepakatan }\end{array}$ \\
\hline
\end{tabular}


is, where the

shortcomings are,

we will complete it

again.
January 8, 2018, and PMK No. 76

of 2016, where

there are still pending claims and still need to be corrected.

This has disturbed the claim flow where the resume should be complete and the diagnostic code must be accurate so that there is no more pending from the BPJS and the hospital bill can be paid by the BPJS quickly and according to the agreement.

\section{PEMBAHASAN}

Berdasarkan telaah dokumen Kebijakan Surat Keputusan Direktur Utama RSUP Dr. M. Djamil Padang YR.01.01/XVI.I/204/2018 Tanggal 8 Januari 2018 tentang Kebijakan Pelayanan/Penyelenggaraan Rekam Medis di RSUP Dr. M. Djamil Padang kelengkapan resume medis dan keakuratan kode diagnosa klaim BPJS rawat inap mengacu pada PMK Nomor 76 Tahun 2016. Berdasarkan cheklist observasi dalam kelengkapan resume medis dan keakuratan diagnosa klaim masih belum maksimal, masih terdapat ketidaklengkapan resume medis dan kode diagnosa yang di pending oleh pihak BPJS. Namun resume yang tidak lengkap serta kode yang tidak akurat tersebut masih bisa di perbaiki, perbaikan dilakukan secara bersama-sama oleh dokter, coder dan case manager. Hasil penelitian yang dilakukan oleh Dewi, menunjukkan bahwa pengisian resume medis yang tidak lengkap dikarenakan masih adanya kekurangan pada data pendukung, seperti indikasi pasien dirawat/diagnosa masuk, diagnosa diferensial dan diagnosa akhir. Deskripsi keakuratan kode diagnosa terdapat kategori akurat (77,5\%) sisanya adalah tidak akurat (22,5\%). Penyebabnya adalah pemahaman coder mengenai kode yang masih kurang (S. C. Dewi, 2012).

Berdasarkan hasil penelitian kelengkapan resume medis dan keakuratan kode diagnosa klaim BPJS rawat inap di Rumah Sakit Umum Pusat Dr. M. Djamil Padang masih belum sesuai dengan Perarturan 
Menteri Kesehatan Nomor 55 Tahun 2013 dam PMK nomor 76 Tahun 2016. Masih ada resume yang tidak lengkap diisi oleh dokter yaitu dari item data pendukung hasil labornya, hasil pemeriksaan fisik yang tidak dituliskan dalam mendukung diagnosa sehingga menyulitkan coder dalam melakukan pengkodean diagnosa. Coder masih ada yang melakukan pengkodean dengan mengandalkan sudah hafal kode tanpa merujuk kembali pada buku ICD 10 dan ICD 9 CM sehingga masih ada kode yang belum cocok dan belum akurat, yang dilihat dari adanya pending Klaim oleh pihak BPJS atau berkas klaim dikembalikan dan belum layak bayar. Informasi medis yang terdapat dalam resume medis tersebut akan mendukung tenaga coder dalam melakukan pengkodean diagnosa secara akurat berdasarkan ICD-10 dan mengacu kepada buku Pedoman PMK Nomor 76 Tahun 2016/Peraturan Menteri Kesehatan Nomor 76 Tahun 2016 tentang Pedoman IndonesianCase Base Groups (INA-CBG) dalam Pelaksanaan Jaminan Sosial Kesehatan Nasional. Keakuratan kode diagnosa sangat mempengaruhi kualitas pembayaran biaya kesehatan dengan sistem case-mix (PMK 76 Tentang Pedoman Indonesian Case Based Groups (INA CBG's) Dalam Pelaksanaan Jaminan Kesehatan Nasional, 2016).

Keakuratan dalam pemberian kode diagnosa merupakan hal yang harus diperhatikan oleh tenaga perekam medis/coder, ketepatan data diagnosa sangat penting dibidang manajemen data klinis dan dalam hal penagihan biaya kepada pihak BPJS Kesehatan beserta hal-hal lain yang berkaitan dalam asuhan dan pelayanan kesehatan (Hatta, 2014). Ketidaklengkapan rekam medis juga dapat mempengaruhi kepuasan dari pasien. Penelitian yang dilakukan oleh Dewi, A., \& Pardede, R. (2020), menunjukkan ada hubungan perilaku kelengkapan rekam medis perawat dengan tingkat kepuasan pasien, dengan $\mathrm{p}=0.000$ dan $\mathrm{OR}=$ 261. Dapat disimpulkan agar pasien puas, maka perawat harus memberikan perilaku kelengkapan rekam medis yang baik karena perilaku kelengkapan rekam medis yang kurang baik berisiko 261 kali untuk terjadinya ketidakpuasan pasien (A. Dewi \& Pardede, 2020). Hasil penelitian Handayani, S., Pardede, R., \& Yuniko, F. (2020), masih rendahnya kelengkapan rekam medis pasien HIV/AIDS pada formulir Ikhtisar perawatan HIV dan terapi antiretroviral disebabkan karena dokter, konselor dan perawat kurangnya perhatian serta tanggung jawab terhadap kelengkapan setiap variabel. Hal ini terjadi karena kurangnya kordinasi antara rekam medis, POKJA/ instalasi khusus HIV, perawat dan dokter untuk melengkapi setiap variable. Selain itu juga karena banyaknya isian dari rekam medis yang harus diisi sehingga penulis juga menyarankan untuk mereduksi kembali list isian pada rekam medis sehingga lebih efisien (Handayani et al., 2020).

Hasil penelitian yang dilakukan oleh Wariyanti (2013), terlihat tingkat kelengkapan dokumen rekam medis dengan kategori lengkap berjumlah 15 $(34,10 \%)$ dan dokumen rekam medis dengan kategori tidak lengkap berjumlah 29 (69,10\%). Dokumen rekam medis dengan tingkat keakuratan diagnosanya akurat sejumlah $18 \quad(59,90 \%)$ dan tidak akurat berjumlah $26 \quad(40,10 \%)$. Dokumen rekam medis dengan tingkat kelengkapan informasi medis 
lengkap dan pemberian kode diagnosa akurat sejumlah $10 \quad(66,67 \%)$, sedangkan dokumen rekam medis dengan tingkat kelengkapan informasi medis lengkap tetapi pemberian kodenya tidak akurat sejumlah 5 $(33,33 \%)$, dokumen rekam medis yang tidak lengkap informasi medis namun akurat sejumlah $8(27,59 \%)$, dan dokumen rekam medis dengan tingkat kelengkapan informasi medis tidak lengkap serta tidak akurat sejumlah 21 (72,41\%). Hal ini disebabkan oleh pengetahuan dan dokter yang tidak patuh dalam mengisi dokumen rekam medis, pengetahuan coder serta kurangnya komunikasi antara coder dengan dokter (Wariyanti, 2016). Oleh karena itu penulis menyarankan kepada dokter untuk lebih teliti dalam mengisi resume medis dan kepada petugas coder untuk lebih teliti dalam melakukan pengkodean serta komunikasi yang baik antara coder dan dokter perlu ditingkatkan, sehingga berkas klaim tagihan pasien BPJS rawat inap bisa dikirimkan kepada pihak BPJS dengan lengkap, akurat, tepat dan tidak ditemukan lagi pending klaim. Lebih lanjut, tagihan rumah sakit dapat dibayarkan dengan segera oleh pihak BPJS Kesehatan kepada rumah sakit

\section{KESIMPULAN DAN SARAN}

Kebijakan pengisian resume medis dan keakuratan kode diagnosa klaim BPJS pasien rawat inap di Rumah Sakit Umum Pusat Dr. M. Djamil Padang sudah mengacu pada Peraturan Menteri Kesehatan Republik Indonesia Nomor 55 Tahun 2013 dan PMK Nomor 76 Tahun 2016. Secara input pihak manajemen perlu perhatian khusus terhadap tenaga, sarana dan prasarana serta sosialisasi kembali terhadap SOP yang telah dibuat. Secara proses pihak manajemen perlu pengawasan yang mnyeluruh dan berkala terhadap kepatuhan petugas dalam melaksanakan SOP yang ada di rumah sakit.

Saran:

1. Diharapkan agar pihak manajemen rumah sakit melakukan pengawasan khusus terhadap kelengkapan resume medis dan pengkodean sehingga tidak terjadi pending klaim BPJS rawat inap pasien secara berulang-ulang.

2. Diharapkan agar pihak manajemen rumah sakit menerapkan resume elektronik sehingga memudahkan dokter dan coder dalam bekerja.

3. Diharapkan agar pihak manajemen mengadakan pertemuan rutin dan berkala baik interen rumah sakit dari seluruh bagian maupun dengan pihak BPJS sehingga mempunyai satu persepsi mengenai tagihan klaim rawat inap.

\section{DAFTAR PUSTAKA}

BPJS, K. (2014). Petunjuk Teknis Verifikasi Klaim BPJS KESEHATAN. 1-46. https://www.bpjs-kesehatan.go.id/b pjs/dmdocuments/Teknis Verifikasi Klaim 7042014.pdf

BPJS, permenkes, \& BPJS. (2014). Panduan Praktis Verifikasi Klaim. Menteri Kesehatan Republik Indonesia, 1-11.

Dewi, A., \& Pardede, R. (2020). HUBUNGAN PERILAKU

KELENGKAPAN REKAM MEDIS DENGAN TINGKAT KEPUASAN PASIEN DIRUANG RAWAT INAP RSUD AROSUKA 
KABUPATEN SOLOK TAHUN 2018. Jurnal Kesehatan Medika Saintika.

https://doi.org/10.30633/jkms.v11i 1.509

Dewi, S. C. (2012). Hubungan Kelengkapan Pengisian Resume Medis dengan Keakuratan Kode Diagnosis Kasus Obstetri Berdasarkan ICD-10 di RSUD DR Moewardi Surakarta. Universitas Muhammadiyah Surakarta.

Handayani, S., Pardede, R., \& ... (2020). KELENGKAPAN REKAM

MEDIK PADA PASIEN HIV/AIDS: $\quad$ LITERATUR REVIEW COMPLETE MEDICAL RECORD IN HIV/AIDS PATIENTS: LITERATURE REVIEW. Jurnal Kesehatan ....

Hatta, G. (2014). Pedoman Manajemen Informasi Kesehatan disarana Pelayanan Kesehatan. In Pedoman Manajemen Informasi Kesehatan disarana Pelayanan Kesehatan.

Kemenkes. (2014). Peraturan Menteri Kesehatan Republik Indonesia Nomor 55 Tahun 2013 Tentang Penyelenggaraan Pekerjaan Perekam Medis. Menteri Kesehatan Republik Indonesia Peraturan Menteri Kesehatan Republik Indonesia.

PMK 76 tentang Pedoman Indonesian Case Based Groups (INA CBG's) dalam Pelaksanaan Jaminan Kesehatan Nasional, Menteri Kesehatan Republik Indonesia (2016).

Saputri, R. O. F. N. (2015). Identifikasi Kelengkapan Informasi Dan Keakuratan Kode Dokumen Rekam Medis Terkait Penentuan Tarif Biaya Pasien Bpjs Di RSUD Pandan Arang Boyolali. In UMS.

Undang Undang Nomor 24 Tahun 2011. (2011). Undang Undang RI Nomor
24 Tahun 2011 Tentang Badan Penyelenggara Jaminan Sosial. Kementerian Hukum Dan Hak Asasi Manusia RI.

Wariyanti, A. S. (2016). Hubungan Antara Kelengkapan Informasi Medis Dengan Keakuratan Kode Diagnosis Pada Dokumen Rekam Medis Rawat Inap Di Rumah Sakit Umum Daerah Kabupaten Karanganyar Tahun 2013. 13. 